\title{
Development of salinity tolerance in the endangered anadromous North Sea houting Coregonus oxyrinchus: implications for conservation measures
}

\author{
Lasse Fast Jensen ${ }^{1, *}$, Dennis Søndergård Thomsen ${ }^{2}$, Steffen S. Madsen ${ }^{3}$, \\ Mads Ejbye-Ernst ${ }^{4}$, Søren Brandt Poulsen ${ }^{5}$, Jon C. Svendsen ${ }^{1,6}$ \\ ${ }^{1}$ Fisheries and Maritime Museum, Tarphagevej 2, 6710 Esbjerg V, Denmark \\ ${ }^{2}$ Ramboll Denmark, Englandsgade 25, 5000 Odense C, Denmark \\ ${ }^{3}$ Department of Biology, University of Southern Denmark, Campusvej 55, 5230 Odense M, Denmark \\ ${ }^{4}$ The Danish Nature Agency, Skovridervej 3, 6510 Gram, Denmark \\ ${ }^{5}$ Department of Biomedicine, Aarhus University, Wilhelm Meyers Allé 3, 8000 Aarhus C, Denmark
}

${ }^{6}$ Interdisciplinary Centre of Marine and Environmental Research, University of Porto, Rua dos Bragas 289, 4050-123 Porto, Portugal

\begin{abstract}
The North Sea houting Coregonus oxyrinchus is an endangered anadromous salmonid belonging to the European lake whitefish complex. The last remaining indigenous population of North Sea houting is found in the River Vidaa, Denmark. Despite legislative protection and numerous stocking and habitat restoration programmes, including a $€ 13.4$ million EU Life restoration project, populations are declining in most rivers in Denmark. Limited knowledge of the general biology of the species, in particular of the early life history stages and habitat requirements, is a serious impediment to management and conservation. In this study, we investigated larval and juvenile salinity tolerance, providing novel information on the early life stages of North Sea houting. Results revealed an ontogenetic differentiation in salinity tolerance when comparing newly hatched larvae, larvae at later developmental stages and juveniles expected to initiate migration to the Wadden Sea. At all developmental stages, larvae exhibited poor hyperosmotic tolerance, while juveniles performed significantly better. Larvae suffered from high mortality and loss of body water at salinities of $18 \mathrm{ppt}$ and higher, while most juveniles survived $30 \mathrm{ppt}$ at least when exposed to gradually increasing salinities. Our results suggest that larval North Sea houting experience very high mortality if carried directly into the Wadden Sea prematurely, highlighting the need for suitable habitat within rivers to retain larvae. Our study shows how different life stages respond differently to varying environmental conditions and emphasizes the need for understanding the physiological mechanisms to improve conservation of endangered species.
\end{abstract}

KEY WORDS: Anadromous $\cdot$ Conservation $\cdot$ Coregonus oxyrinchus $\cdot$ Habitat restoration $\cdot$ North Sea houting $\cdot$ Ontogeny $\cdot$ Osmoregulation $\cdot$ Salinity tolerance $\cdot$ Whitefish

\section{INTRODUCTION}

The North Sea houting Coregonus oxyrinchus is an endangered fish species endemic to the Wadden Sea and listed in the Bern Convention as well as in Appendixes II and IV in the EU Habitats Directive (Pihl et al. 2000). The North Sea houting is an anadromous salmonid belonging to the European lake

${ }^{*}$ Corresponding author: lfj@fimus.dk whitefish species complex (Jacobsen et al. 2012). Its taxonomic status, however, has been subject to discussions. Thus, Freyhof \& Schöter (2005) investigated variation in morphological traits and suggested that C. oxyrinchus was confined to the Rhine and became extinct. This view was adopted by the International Union for the Conservation of Nature (IUCN), and thus the status of $C$. oxyrinchus on the IUCN Red List 
is listed as 'Extinct'. However, some of the traits that Freyhof \& Schöter (2005) analysed are known to be homoplastic in whitefish (Østbye et al. 2005, 2006, Etheridge et al. 2012), and their conclusion has been questioned based on comprehensive genetic evidence (Jacobsen et al. 2012).

The historical geographical distribution of the North Sea houting most likely encompassed the entire Wadden Sea area from Skallingen in Denmark in the north to the Dutch Den Helder in the south. However, eradication of spawning and nursery areas, canalization of rivers, establishment of weirs and dams, building of dikes and sluices, pollution and commercial fishing for whitefish in the rivers led to dramatic declines of populations (De Groot \& Nijssen 1997, De Groot 2002, Jensen et al. 2003). In the winter of $1978 / 79$, a survey revealed that this previously abundant species was on the brink of extinction, and that only 1 population remained in the world, in the Danish River Vidaa (Grøn 1987, Jensen et al. 2003). In an attempt to save the species from extinction, a stocking programme was launched in 1982, releasing a total of 1.7 million juvenile North Sea houting into a few Danish rivers. Concurrently, the North Sea houting was reintroduced into a few rivers in Germany based on brood stock from the River Vidaa (Jäger 1999). The Danish stocking programme ended in 1992 (Jensen et al. 2003), but stocking still takes place in Germany (Dierking et al. 2014). Several river restoration projects, including a $€ 13.4$ million (US $\$ 15.2$ million) restoration project in 2005 (Hansen 2006), have been carried out aiming at removing migration barriers for adults migrating into the rivers to spawn and establishing suitable nursery habitat for larvae and juveniles.

Despite legislative conservation measures and river restoration projects, the Danish populations of North Sea houting are declining. In the Rivers Sneum, Brede and Konge, populations were reestablished during the course of the stocking programme, but lack of natural recruitment means that populations are approaching extirpation (Jepsen et al. 2012). Natural reproduction has also been very limited in the River Ribe for several years, and this population is now mostly made up of a few old cohorts (Jepsen et al. 2012). Likewise, in the River Varde, the population has declined dramatically. Thus, during a survey in November 2013, only 5 North Sea houting were caught in the River Varde, the lowest number caught since the launch of the survey in 1989 (M. Deacon pers. comm.). Only the River Vidaa is home to a relatively stable population with natural reproduction taking place regularly, although recent monitoring suggests that the population has declined within the last 4 yr. Exact population size estimates are not available, but the population is thought to total 4000 individuals in the River Vidaa (Jensen et al. 2003). Hansen et al. (2006) estimated that the genetic effective population size of the River Vidaa population is just above 500 individuals and concluded that the population is not under any immediate threat from inbreeding or loss of adaptive potential. However, the fact that the indigenous remnants of this species are only naturally reproducing in a single location at a global scale is of great concern and calls for action towards improvement of the reproductive output in other populations.

One of the greatest hurdles hindering proper management and conservation of the North Sea houting is the lack of biological knowledge about the species. Adults are known to undertake spawning migrations in November and December from the saline Wadden Sea into rivers, where they spawn the eggs freely in the water. Eggs are thought to adhere to gravel and underwater vegetation. Little is known about the environmental factors that trigger the spawning migration, although, based on telemetry data, Borcherding et al. (2014) suggested that photoperiod, temperature and discharge may play a role.

After spawning, the adults return to the Wadden Sea to forage. This downstream migration normally takes place during winter and early spring, although it has not been investigated in detail. Information about the early life stages is scarce, but it is generally assumed that the larvae hatch in February and March and stay within lentic water in lakes and flooded meadows the first few months (Jensen et al. 2003, Borcherding et al. 2006). In May and June, juvenile North Sea houting, measuring 3 to $5 \mathrm{~cm}$ in total length, have been caught in the Wadden Sea just outside the river mouths, indicating that the juveniles enter seawater at this size (Rasmussen 2004). Analyses of mineral composition in scale samples support this observation (Borcherding et al. 2008). Whether larvae and juveniles of North Sea houting actively migrate or are passively carried by the current remains uncertain. Borcherding et al. (2006) observed that juveniles of North Sea houting stocked into the Lippe River, a tributary to the Lower Rhine, arrived in downstream regions along with the water in which they were stocked, indicating passive drift due to water velocities exceeding maximum swimming speeds. However, these authors also found an active size-dependent component in the diel drift pattern. Similarly, studies have revealed that larvae are capable of swimming (Poulsen et al. 2010, 2012), 
and that juveniles may actively discontinue migration when the energetic state is insufficient (Poulsen et al. 2010).

The anadromous life of the North Sea houting challenges its osmoregulatory capacity. While in freshwater, the osmotic concentration in the surrounding environment is much lower than in the body fluids of the fish. Hence, osmotic water inflow and loss of solutes risk diluting body fluids (Schmidt-Nielsen 1997). To compensate, fish produce large quantities of dilute urine and actively take up solutes in specialized ionocytes in the gill epithelia. Moving from freshwater to saltwater habitats calls for extensive physiological remodelling. In saltwater, the osmotic concentration is higher in the surrounding environment than within the fish, and the fish risk losing vital water by diffusion, particularly across the gills, if they do not compensate by drinking saltwater and excreting solutes (Marshall 1995). Hence, anadromous fish need mechanisms to switch from hyperosmoregulation to hypo-osmoregulation as they move from freshwater to saltwater. Osmotic stress and related mortality is well documented in many anadromous fish species (Yeoh et al. 1991, McCormick 1994, Zydlewski \& McCormick 1997, Varsamos et al. 2005). It is therefore imperative to understand vulnerability to osmotic stress across life stages of anadromous species to improve conservation efforts.

Whether larval or juvenile North Sea houting develop increased salinity tolerance during ontogeny, and at which body size or age they can tolerate the high salinities encountered in the Wadden Sea, is unknown. However, information on the importance of the timing of arrival in seawater has clear management and conservation implications and is of relevance to restoration practices. Larvae and juveniles carried prematurely into the Wadden Sea due to increased current velocities resulting from anthropogenic alterations of river systems are expected to suffer from high mortality if salinity tolerance develops in concert with larval growth. Therefore, in this study, we analysed ontogenetic differentiation of salinity tolerance in larval and juvenile North Sea houting and relate the findings to the timing of the arrival of juveniles in the Wadden Sea. Specifically, we measured salinity survival, body water content and drinking rate in larvae and juvenile North Sea houting ranging between 7.5 and $690 \mathrm{mg}$. While salinity survival can be due to either tolerance of high concentrations of electrolytes in tissues or actual osmoregulation, drinking rate and body water content both reflect the ability to maintain water balance and actively osmoregulate.

\section{MATERIALS AND METHODS}

\section{Fish}

Migrating adult North Sea houting were captured by electrofishing in November and December 2001 in the River Varde, Denmark. Two females and 6 males were stripped for eggs and milt, respectively, and eggs from each female were fertilized with milt from 3 males. The fertilized eggs were transferred to plastic bags containing river water $\left(4^{\circ} \mathrm{C}\right)$ and transported to the University of Southern Denmark in Odense. In the laboratory, eggs were placed in a single layer in plastic trays ensuring minimal contact between the individual eggs to avoid fungal infection. Eggs were inspected daily and dead eggs removed regularly. Water temperature was kept at $4^{\circ} \mathrm{C}$ during incubation.

Hatching took place between 30 January and 16 March, with the vast majority of larvae hatching in early March. The number of degree days from fertilization to hatching for most larvae ranged between 360 and 412. A total of 5500 larvae were available for the study. The newly hatched larvae were transferred to 101 aquaria (200 ind. aquarium ${ }^{-1}$ ) with aerated water from the nearby River Lindved. Water was changed partially 2 to 3 times a week and constantly aerated. Water oxygen saturation was monitored regularly (YSI 85 oxygen electrode) and kept above $70 \%$ air saturation. Water temperature was gradually increased and reached $13^{\circ} \mathrm{C}$ in May. Later, fish were transferred to large flow-through tanks (400 l) with aerated water. Throughout the experiment, fish were fed freshly hatched Artemia salinas larvae.

All experimental procedures were approved by the Danish Animal Experiments Inspectorate in accordance with the European Convention for the Protection of Vertebrate Animals used for Experiments and other scientific Purposes (no. 86/609/EØF).

\section{Salinity survival}

Two protocols were used to assess salinity tolerance in larvae and juveniles. Specifically, survival in various salinities was determined after: (1) direct separate transfers from freshwater (0 ppt) to either 10, 18, 25 or 30 ppt saltwater (Protocol A), and (2) stepwise increases of salinity from 10 to $30 \mathrm{ppt}$ using steps of 5 ppt every fourth day (Protocol B). Different salinities were produced from water originating from the River Lindved mixed with Coral Reef Red Sea Salt (Red Sea). Salinity was measured using a YSI 85 probe and a Wescor 5500 vapour pressure osmometer. For each 
treatment, average body weights and total lengths were estimated using 10 randomly selected individuals. Experimental fish were fasted for $24 \mathrm{~h}$ before each trial. Larvae or juveniles were transferred to the test aquaria (10 1), and dead individuals were counted after $1,2,3,4,6,24,48,72,96,120,144$ and $168 \mathrm{~h}$ when fish were directly transferred to saltwater (i.e. Protocol A) and every $24 \mathrm{~h}$ when the stepwise increases of salinity were applied (Protocol B). In addition, feeding and swimming activity of surviving fish were evaluated. Fish were fed for the first time $6 \mathrm{~h}$ into the experiment and subsequently every $12 \mathrm{~h}$.

For the survival tests applying direct transfer into saltwater (Protocol A), fish were divided into 4 groups according to age (days after hatching): A1: 0-4 d old larvae, average weight $7.5 \mathrm{mg}$, average total length $12.1 \mathrm{~mm}$; A2: 15-19 d old larvae, average weight $7.9 \mathrm{mg}$, average total length $12.6 \mathrm{~mm}$; A3: 32-35 d old larvae, average weight $10.4 \mathrm{mg}$, average total length $13.0 \mathrm{~mm}$; A4: 148-166 d old juveniles, average weight $141 \mathrm{mg}$, average length $33.6 \mathrm{~mm}$. For groups $\mathrm{A} 1-\mathrm{A} 3$, water temperature was $5 \pm 1{ }^{\circ} \mathrm{C}$ and 80 ind. were used at each salinity. For group A4, water temperature was $12 \pm 1^{\circ} \mathrm{C}$ and 50 ind. were used at each salinity. Water temperature reflected the water temperatures that the respective larvae and juveniles are exposed to in the wild.

For the survival tests applying a stepwise increase of salinity (Protocol B), fish were divided into 2 groups according to age: B1: $44-48$ d old larvae, average weight $13.1 \mathrm{mg}$, average total length $13.8 \mathrm{~mm}$; B2: 255-273 d old juveniles, average weight $690 \mathrm{mg}$, average total length $50 \mathrm{~mm}$. For each of the 2 groups (B1 and B2), individuals were divided into a control group (80 ind.) kept in freshwater (0 ppt) throughout the experiment and an experimental group (80 ind.) exposed to increasing salinities starting at $10 \mathrm{ppt}$. Subsequently, salinity was increased 5 ppt every fourth day $\left(1 \mathrm{ppt} \mathrm{h}^{-1}\right)$ until a salinity of 30 ppt was reached. For group B1, water temperature was $5 \pm 1^{\circ} \mathrm{C}$, while the temperature for group B2 was $13 \pm 1^{\circ} \mathrm{C}$.

\section{Body water content measurements}

Body water content was measured at the same salinities and for the same groups as for the salinity survival tests (A1-A4 and B1-B2). Fish were fasted $24 \mathrm{~h}$ prior to the start of the experiment, and no food was supplied throughout the experiment. After $4 \mathrm{~h}$ and $24 \mathrm{~h}, 10$ fish were sampled and sacrificed by penetrating the head with a needle. After removal of excessive water from the skin using a paper napkin, fish were weighed to the nearest $0.1 \mathrm{mg}$ (wet mass: $M_{\mathrm{W}}$ ) and dried in an oven at $100^{\circ} \mathrm{C}$ for $24 \mathrm{~h}$ and then weighed again (dry mass: $M_{\mathrm{D}}$ ). Body water content $(\mathrm{BWC})$ was estimated as BWC $=\left(M_{\mathrm{W}}-M_{\mathrm{D}}\right) / M_{\mathrm{W}}$.

\section{Drinking rate measurements}

Drinking rate was estimated for juveniles aged 180-200 d old (mean weight $175 \mathrm{mg}$ ) in freshwater $(0 \mathrm{ppt})$ and saline water (18 and $25 \mathrm{ppt})$ using a radioactive tracer (Usher et al. 1988). Fish were acclimated in the respective salinities for $14 \mathrm{~d}$ before they were transferred to water containing the radioactive tracer ${ }^{51} \mathrm{Chromium}$-EDTA $\left(3.7 \times 10^{5} \mathrm{~Bq}^{-1}\right)$. Fish were incubated for $2 \mathrm{~h}$, transferred to non-radioactive water for $2 \mathrm{~h}$ to rinse skin and gills and subsequently sacrificed, weighed and individually placed into scintillation vials for radioactivity counts. The drinking rate (DR) in $\mathrm{ml} \mathrm{kg}^{-1} \mathrm{~h}^{-1}$ was estimated as follows:

$$
\mathrm{DR}=\frac{\mathrm{CPM} \text { fish } \times 60 \times \text { sample volume }}{\text { CPM water } \times \text { weight } \times \text { time }}
$$

where CPM is radioactivity measured in counts per minute, sample volume is volume of water measured for radioactivity $(\mathrm{ml})$, weight is fish body mass $(\mathrm{g})$, and time is incubation time in water containing radioactive tracer (h).

\section{Statistical analyses}

Statistical analyses of survival were performed by fitting univariate generalized linear models (GzLM) assuming a Poisson distribution with log linear link function. Statistical analyses of body water content and drinking rate were performed by fitting univariate general linear models (GLM). Normality of data was evaluated using Shapiro-Wilk tests (Shapiro \& Wilk 1965). Statistical analyses were performed using SPSS version 20 (IBM). Correction for multiple tests using the Bonferroni procedure was applied in all post hoc tests.

\section{RESULTS}

\section{Salinity survival}

Protocol A1 (direct transfer, 0-4 d old larvae)

At 0 and $10 \mathrm{ppt}$, survival of newly hatched larvae was $100 \%$ throughout the duration of the experi- 
ment, and the larvae were active and feeding (Fig. 1). At 18 ppt, larvae showed signs of stress (lying passively on the bottom) after $96 \mathrm{~h}$. After $168 \mathrm{~h}$, survival was $96 \%$ and all larvae alive were lying at the bottom. At 25 ppt, survival was $89 \%$ after 48 h, 68\% after $72 \mathrm{~h}$ and $0 \%$ after $96 \mathrm{~h}$. At $30 \mathrm{ppt}$, survival was $98 \%$ after $24 \mathrm{~h}$ and $0 \%$ after $48 \mathrm{~h}$.

\section{Protocol A2 (direct transfer, 15-19 d old larvae)}

All larvae were alive and actively feeding in freshwater (0 ppt) and 10 ppt saltwater after 168 h (Fig. 1).
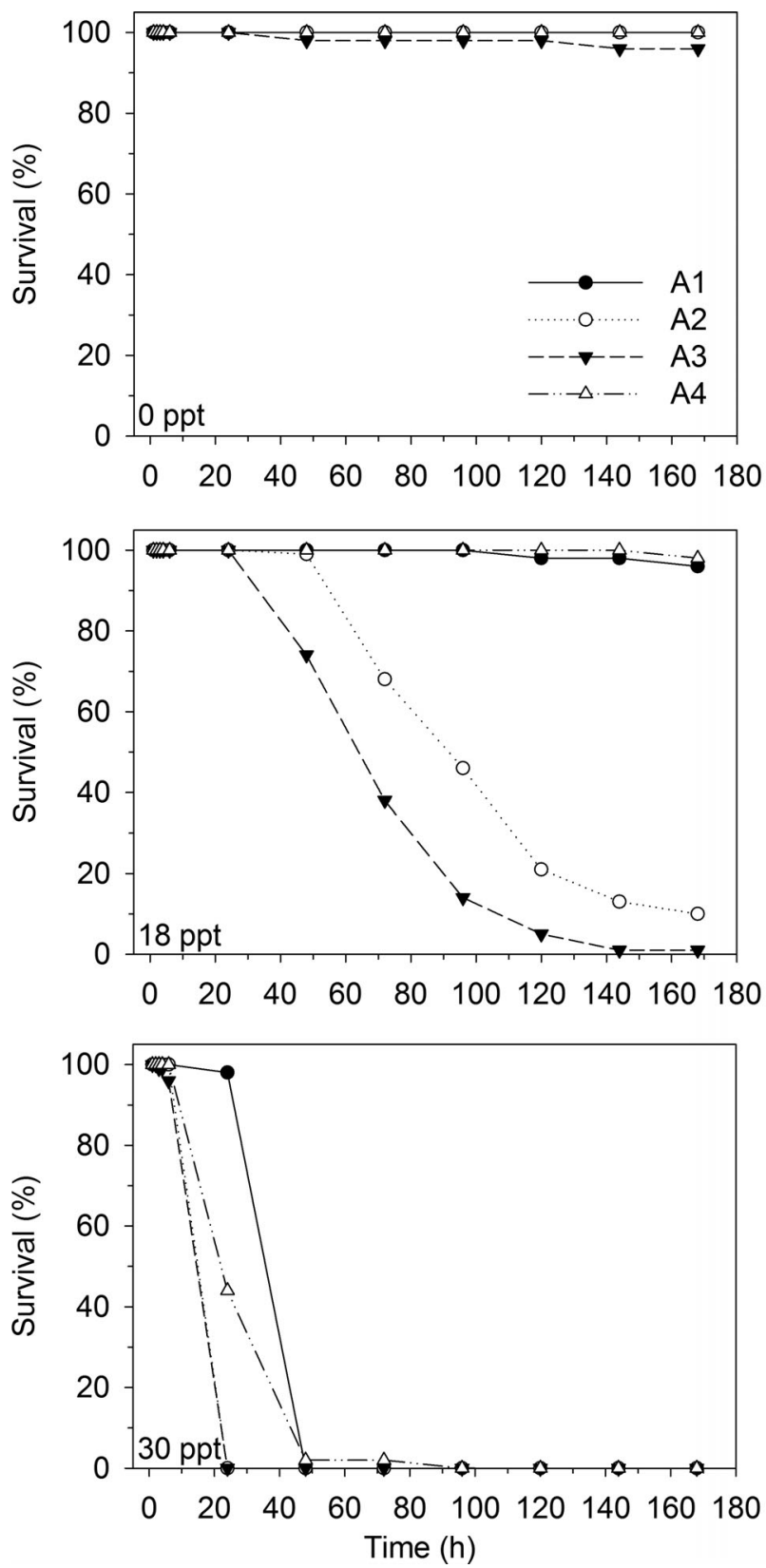

At $18 \mathrm{ppt}$, the larvae showed signs of stress after $24 \mathrm{~h}$, and after $48 \mathrm{~h}$ and $72 \mathrm{~h}$, survival was $99 \%$ and $68 \%$, respectively. After 168 h, survival was $10 \%$, and only half of the larvae alive were active. At 25 ppt, survival was $94 \%$ after $24 \mathrm{~h}$ and all larvae were inactive. After 48 h, survival was $4 \%$, and after 72 h, no larvae were alive. At 30 ppt, survival was $0 \%$ after $24 \mathrm{~h}$.

Protocol A3 (direct transfer, 32-35 d old larvae)

Survival was $96 \%$ at 0 ppt after 168 h (Fig. 1), while at $10 \mathrm{ppt}$, all larvae were alive and active at the end of
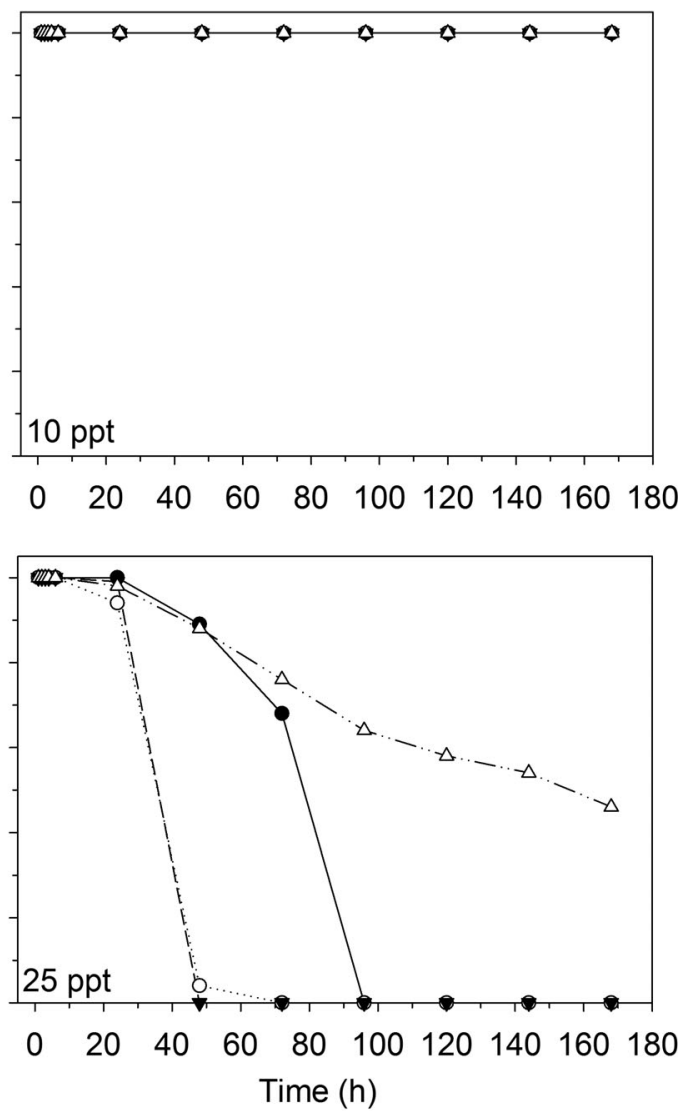

Fig. 1. Relative survival of larval and juvenile North Sea houting Coregonus oxyrinchus at different development stages and different salinities $(0,10,18,25$ and $30 \mathrm{ppt})$. A1: 0-4 d old larvae; A2: 15-19 d larvae; A3: 32-35 d larvae; A4: 148-166 d old juveniles 
the experiment (i.e. after $168 \mathrm{~h}$ ). At $18 \mathrm{ppt}$, survival was $100 \%$ after $24 \mathrm{~h}$, although only half of the larvae were active. After 48, 72 and 96 h, survival was 74, 38 and $14 \%$, respectively. After $168 \mathrm{~h}$, only $1 \%$ of the larvae were alive. At 25 pt, survival was $99 \%$ after $24 \mathrm{~h}$, but $90 \%$ of the larvae were inactive. After 48 h, no larvae were alive. At 30 ppt, survival was $0 \%$ after $24 \mathrm{~h}$.

Protocol A4 (direct transfer, 148-166 d old juveniles)

Survival was $100 \%$ throughout the experiment at 0 and 10 ppt (Fig. 1). At 18 ppt, all juveniles were alive and active after 96 h; after 168 h, survival was 98\% and no juveniles showed signs of stress. At $25 \mathrm{ppt}$, survival was 98, 88 and $76 \%$ after 24,48 and $72 \mathrm{~h}$, respectively. After $96 \mathrm{~h}$ and $168 \mathrm{~h}$, survival was $64 \%$ and $46 \%$, respectively, and the juveniles were actively feeding. At 30 ppt, survival was $44 \%$ after $24 \mathrm{~h}$, but after $48 \mathrm{~h}$ and $72 \mathrm{~h}$, only $2 \%$ were alive, but active. After 96 h, no juveniles were alive.

A significant effect of salinity $(\mathrm{p}<0.01)$, age $(\mathrm{p}<$ $0.01)$ and time $(p<0.01)$ on survival after direct transfer as well as a significant interaction between age and salinity $(\mathrm{p}<0.01)$ was identified (Table S1 in the Supplement at www.int-res.com/articles/suppl/n028 p175_supp.pdf). Post hoc tests indicated significant differences in survival between all salinities in 15-19 and 32-35 d old larvae, except between 25 and 30 ppt and between 0 and 10 ppt. In contrast, in 0-4 d old larvae and 148-166 d old juveniles, a significant effect of salinity was found at salinities of $25 \mathrm{ppt}$ and above (Table S2a). Contrasting age groups revealed significant differences at salinities $18 \mathrm{ppt}$ and $25 \mathrm{ppt}$ in A1 vs. A2, A1 vs. A3, A2 vs. A4 and A3 vs. A4 (Table S2B). These findings indicate that survival was strongly dependent on age and salinity and that fish of different ages responded differently to varying salinities. Survival in elevated salinities was higher in older fish.

Protocols B1 and B2 (stepwise increase, 44-48 d old larvae and 255-273 d old juveniles)

Fig. 2 shows the survival in 44-48 d old larvae and 255-273 d old juveniles when gradually increasing salinity from 10 to 30 ppt over a period of $480 \mathrm{~h}$. A significant effect of age $(p<0.01)$, time $(p<0.01)$ and salinity $(p<0.01)$ as well as a significant interaction between age and salinity $(p<0.01)$ was identified. In addition, differences between experimental groups and control groups were statistically significant $(p<0.01)$.
For 44-48 d old larvae (Fig. 2A), survival after $96 \mathrm{~h}$ was $100 \%$ in both the experimental group at $10 \mathrm{ppt}$ and the control group kept at 0 ppt throughout the experiment. At this time point, salinity was gradually increased to 15 ppt, and after 120 h survival was $99 \%$ in both groups. After $192 \mathrm{~h}$ (15 ppt), survival was $95 \%$ in the experimental group and $94 \%$ in the control group. However, $40 \%$ of the experimental larvae were lying inactive on the bottom, while all larvae in the control group were active. At 20 ppt and higher (192 h), survival started to decline drastically in the experimental group, and the proportion of inactive larvae increased, while the survival in the control group remained relatively high and the larvae remained active throughout the experiment. At 25 ppt, mortality rate in the experimental group remained high, and after $432 \mathrm{~h}$, no larvae were alive. These findings showed that larvae were intolerant to salinities above 20 ppt, even when salinity was increased gradually.

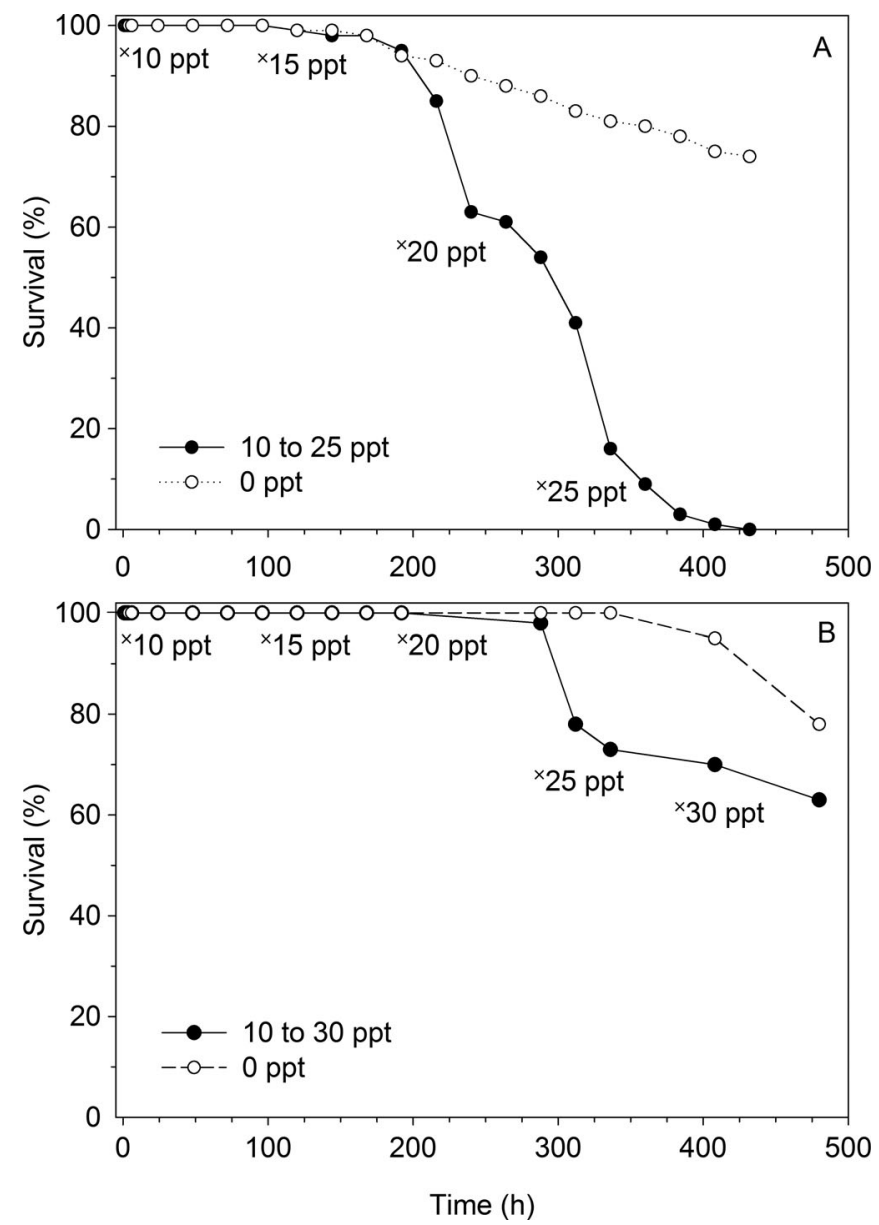

Fig. 2. Relative survival of (A) 44-48 d old larval North Sea houting Coregonus oxyrinchus and (B) 255-273 d old juveniles under gradual increase in salinity (10 to $30 \mathrm{ppt}_{\text {; }}$ the numbers in the plot show the time point $\left[{ }^{\times}\right]$at which salinity was increased to the given salinity) 
For 255-273 d old juveniles, survival was high in both the experimental group and control group up to 25 ppt (Fig. 2B). At this salinity, survival started to decrease. After $48 \mathrm{~h}$ at $25 \mathrm{ppt}$, survival dropped to $73 \%$, but all remaining juveniles were active and feeding. After increasing the salinity to $30 \mathrm{ppt}$, survival decreased to $63 \%$ at the termination of the experiment. All juveniles alive remained active and feeding. The observed drop in survival which occurred from 25 to 30 ppt could be due to causes other than salinity, as survival in the control treatment also declined after $400 \mathrm{~h}$.

\section{Body water content measurements}

Fig. 3 shows body water content in the 4 age groups after 4 and $24 \mathrm{~h}$ of exposure to freshwater (0 ppt) and different salinities. Significant effects of time $(\mathrm{p}=0.001)$, age $(\mathrm{p}=0.001)$ and salinity $(\mathrm{p}=$ 0.001 ) were identified, as well as significant interac-
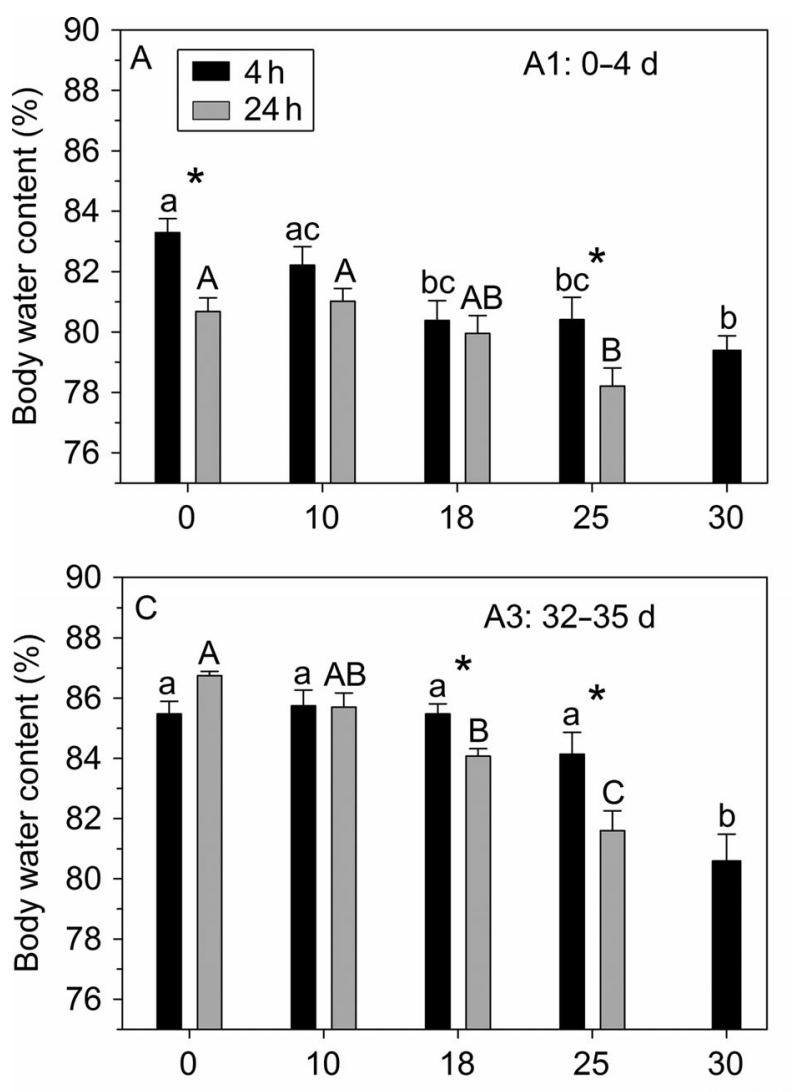

tion terms between all factors $(p=0.001$ for all interactions). Hence, body water content not only differed between ages and salinities, but the way body water content changed in response to salinity differed between age groups as well as exposure times.

In all age groups, body water content decreased at increasing salinity, and in 0-4, 15-19 and 32-35 d old larvae, the decrease continued from 4 to $24 \mathrm{~h}$. However, 148-166 d old juveniles did not experience further loss of body water from 4 to $24 \mathrm{~h}$, indicating that they were able to stabilize their water balance by osmoregulating. Body water content was not measured in any age group after $24 \mathrm{~h}$ at $30 \mathrm{ppt}$ due to high mortalities.

A significant effect of treatment, i.e. control vs. increasing salinity, on body water content in 44-48 d old larvae (protocol B1) and 255-273 d old juveniles (protocol B2) exposed to gradual increases of salinity was identified ( $p<0.01)$, as well as a significant effect of age $(p<0.01)$ and salinity $(p<0.01)$. Post hoc tests revealed a significant difference in body water con-
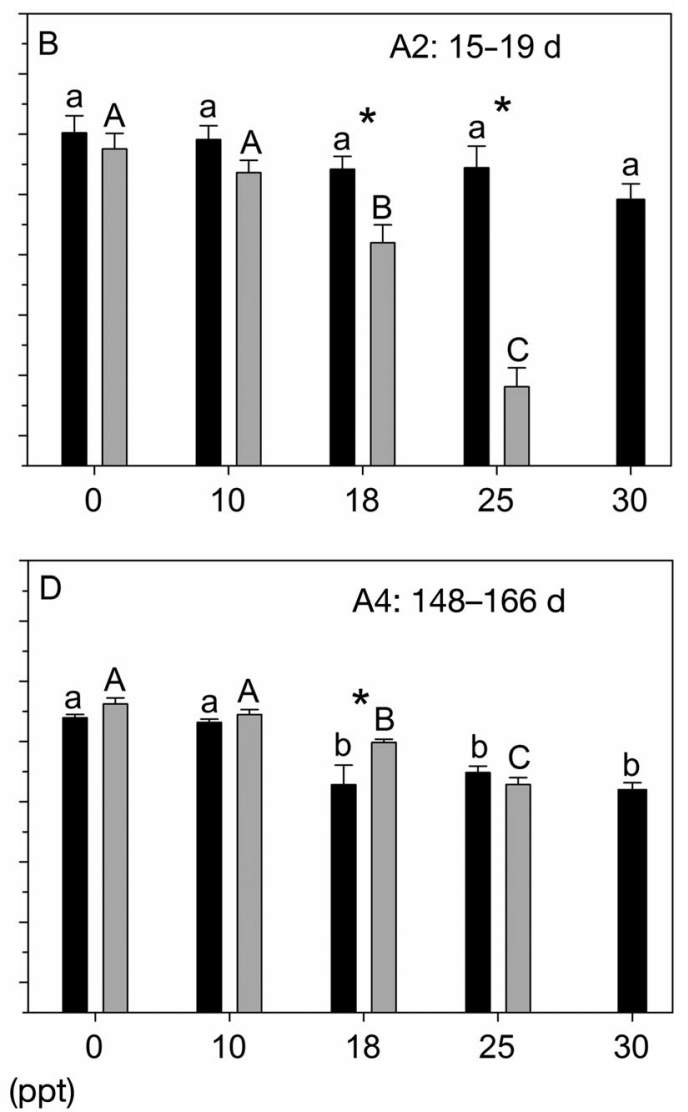

Fig. 3. Body water content in North Sea houting Coregonus oxyrinchus after 4 and $24 \mathrm{~h}$ of exposure at different developmental stages (A1: 0-4 d old larvae; A2: 15-19 d larvae; A3: 32-35 d larvae; A4: 148-166 d old juveniles) and different salinities. Values are mean $\pm \operatorname{SE}(n=10)$. Asterisks denote significant difference at $\mathrm{p}<0.05$, between 4 and $24 \mathrm{~h}$ after correction for multiple comparisons. Different letters on bars designate statistically significant differences $(p<0.05)$ after correction for multiple comparisons. Lower case letters refer to $4 \mathrm{~h}$; upper case letters refer to $24 \mathrm{~h}$ 
tent in larvae when comparing the control group at $0 \mathrm{ppt}$ and the experimental group at $20 \mathrm{ppt}$ ( $\mathrm{p}=$ 0.002). In juveniles, a significant difference in body water content was found between the control group and the experimental group at $15 \mathrm{ppt}(\mathrm{p}=0.007)$. At 20 and 25 ppt, however, no differences between control groups and experimental groups were observed. These findings indicate that larvae were unable to maintain body water at 20 ppt, while juveniles hypoosmoregulated at 20 and 25 ppt, when gradually acclimated to increasing salinities.

\section{Drinking rate measurements}

Drinking rate in juveniles (180-200 d old) exposed to salinities of 0,18 or 25 ppt for $2 \mathrm{~h}$ are shown in Fig. 4. A significant effect of salinity $(p=0.005)$ was identified, and post hoc tests revealed a significant difference between 0 and 25 ppt $(p=0.004)$. These findings suggest that juveniles aged 180-200 d old increase drinking rate as a response to increasing salinities.

\section{DISCUSSION}

In this study, we found evidence of ontogenetic differentiation of salinity tolerance when comparing larval and juvenile North Sea houting. After direct

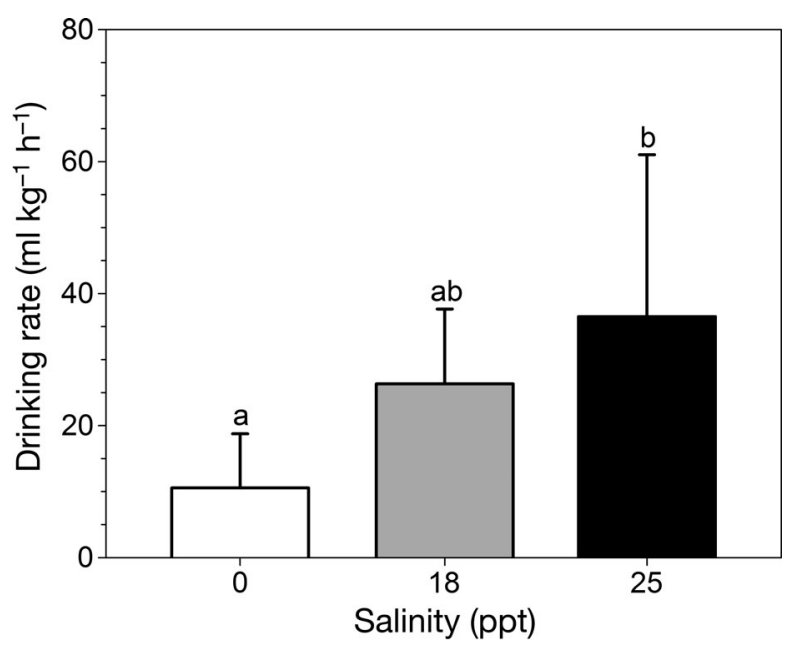

Fig. 4. Drinking rate of 180-200 d old juvenile North Sea houting Coregonus oxyrinchus at different salinities. Bars show the drinking rate changes after $2 \mathrm{~h}$ of incubation in water of the respective salinity supplemented with ${ }^{51} \mathrm{Chromium}$ EDTA $\left(3.7 \times 10^{5} \mathrm{~Bq} \mathrm{l}^{-1}\right)$ followed by $2 \mathrm{~h}$ of rinsing. Values are mean \pm SE $(n=10)$. Different letters on bars designate statistically significant differences $(\mathrm{p}<0.05)$ transfer to artificial seawater, juveniles exhibited significantly higher survival over time than larvae, indicating improved hyperosmotic tolerance. A gradual increase in salinity yielded concordant results, and the ontogenetic differentiation of salinity tolerance was also evident when assessing body water content. The effect of increasing salinity on body water content was less profound in juveniles than in larvae. Thus, hyperosmotic tolerance improved as the larvae increased in size. The increased drinking rate in juveniles at increasing salinities suggests that juvenile North Sea houting are capable of osmoregulating in saltwater. Newly hatched larvae represented an exception from the general pattern and exhibited similar survival to the juveniles when directly transferred into saltwater. However, although survival was relatively high, newly hatched larvae showed clear signs of severe osmotic stress (inactive behaviour) at salinities of 18 ppt and higher, while juveniles remained active and feeding. The reason for the relatively high survival in 0-4 d old larvae is currently unknown. Technical issues cannot be ruled out, however, and the establishment of a number of parallel independent replications could possibly have indicated whether this represents an outlying observation or a general pattern.

The development of increased salinity tolerance observed in juveniles in the present study coincides with the size and age at which juveniles have been observed in the estuarine areas outside of river mouths. Evaluating the occurrence of juvenile North Sea houting in the Wadden Sea, Rasmussen (2004) caught juveniles in pound nets placed just outside the outlet of the River Vidaa in May and June. The juveniles caught measured 38 to $59 \mathrm{~mm}$ in total length, and gut analyses revealed that several of them had been feeding in saltwater. Mud shrimp Corophium volutator, marine snails Potamopyrgus jenkinsii, mysid crustaceans Neomysis integer and different species of polychaetes represented the major part of the gut contents. Hence, these juveniles seemingly possessed an improved hyperosmotic tolerance, allowing them to feed in seawater. It could therefore be speculated that they were not carried into the Wadden Sea prematurely. The juvenile North Sea houting used in the current study measured on average $33.6 \mathrm{~mm}$ and $50.0 \mathrm{~mm}$ in the direct and graduate salinity transfer tests, respectively, and are within the size range of the juveniles observed in saltwater in the wild. The increased salinity tolerance observed in the juveniles is most likely due to preparation of the fish to the transition from freshwater to saltwater. Similar increases in hyperosmotic toler- 
ance are known for juveniles of other salmonid species that are preparing for the marine environment (e.g. Nielsen et al. 2001, 2003, 2004).

In larvae aged 44-48 d old, a gradual increase in salinity to 20 ppt induced a high mortality, and $45 \%$ of the surviving fish were inactive, indicating osmotic stress. Thus, even when exposed to gradually increasing salinities, larvae were not capable of tolerating salinities above $20 \mathrm{ppt}$. On the other hand, in juveniles aged 255-273 d old, survival was high even at 25 and 30 ppt when exposed to gradual increases in salinity. These fish seemed to perform better than juveniles aged 148-166 d old and exposed to direct transfer to high salinities. However, whether this improved survival is due to an effect of acclimation per se or to the difference in age cannot be determined. Thus, hyperosmotic tolerance in juvenile North Sea houting might continue to increase during growth. In brown trout Salmo trutta and Atlantic salmon S. salar (Shrimpton et al. 2000), which are anadromous salmonids, juveniles physiologically prepared for migrating from freshwater to saltwater (i.e. smolts) lose the ability to hypo-osmoregulate after some time when restricted from migrating and they revert physiologically to remaining in freshwater. Evidence from North Sea houting within the Rhine River system indicates that a proportion of juveniles postpones or even refrains from migration (Borcherding et al. 2008). Future studies should look into whether juvenile North Sea houting lose the ability to hypo-osmoregulate at some point if restricted from migration as well as into the physiological changes in North Sea houting in relation to variation in migratory behaviour.

The ontogenetic development in salinity tolerance has clear implications for the management of North Sea houting. Most of the rivers in the Wadden Sea area have been channelized in large sections, resulting in increased longitudinal water current velocities. Also, dikes on the river banks have been established, keeping the rivers from flooding meadows and low land, particularly in winter and spring. These habitat alterations might increase the risk of larval and juvenile North Sea houting being carried into the Wadden Sea prematurely. The poor hyperosmotic tolerance of larval North Sea houting found in the present study suggest that premature arrival in the Wadden Sea would be associated with very high mortality. Poulsen et al. (2012) analysed ontogenetic differentiation in swimming performance in larval and juvenile North Sea houting and found that maximum swimming speed is $9.4 \mathrm{~cm} \mathrm{~s}^{-1}$ in larvae measuring $13 \mathrm{~mm}$. For juveniles measuring $31 \mathrm{~mm}$, maxi- mum swimming speed is $25.2 \mathrm{~cm} \mathrm{~s}^{-1}$. Routine swimming speeds were considerably lower, i.e. 4.6 and $16.3 \mathrm{~cm} \mathrm{~s}^{-1}$ in larvae and juveniles, respectively. Compared to current velocities in those areas where North Sea houting are assumed to spawn, larvae and juveniles would be carried downstream in $85-95 \%$ of the water column. Borcherding et al. (2006) observed North Sea houting being carried downstream in the River Lippe, which is a tributary of the lower Rhine. Newly stocked juvenile North Sea houting arrived at downstream positions at the same time as the water into which they had been stocked, indicating that they were carried downstream by the current. However, at the same time, increased drift activity of larger larvae was observed after dusk, indicating a size-dependent active behavioural component to the diel drift pattern. To what degree larvae and juveniles actively locate and exploit sheltered areas with low water velocities is unknown, but Poulsen et al. (2012) found that habitat complexity reduces downstream migration speed in indoor stream channels. Establishing an increased number of meanders and a higher level of habitat complexity within the rivers and allowing the rivers to flood the meadows during winter and spring could increase retention of larvae and juveniles. As indicated in the present study, juveniles might need a period of acclimation to gradually increasing salinities before they can tolerate high salinities. Thus, juvenile North Sea houting may need to take hold in the lower tidal parts of rivers and estuarine areas for a period of time before they are able to move into the Wadden Sea, and establishing areas with low current speeds and high habitat complexity in these areas may help improve survival during the critical transition from freshwater to saltwater. However, more research is needed before actual habitat restoration guidelines targeting larval and juvenile North Sea houting can be provided. For instance, a better understanding of the habitat types that favour survival in larval and juvenile North Sea houting is urgently needed to protect the habitat in the River Vidaa and promote habitat in other river systems draining into the Wadden Sea. Also, the extent to which larvae are actually carried prematurely into the Wadden Sea needs to be investigated further. Rasmussen (2004) caught North Sea houting larvae measuring on average $12.1 \mathrm{~mm}$ in driftnets in the lower reaches of River Ribe, indicating that larvae in this river system are carried into the Wadden Sea prematurely. However, the proportion of hatching larvae ending up in the lower reaches and the extent to which they were actually carried into the Wadden Sea was not quantified. 
Restoration projects have aimed to provide nursery areas for larval and juvenile North Sea houting by creating lakes within river systems. These lakes could serve to retain larval and juvenile North Sea houting, thereby reducing premature arrival in the Wadden Sea. In an effort to attain good status of water bodies within the context of the EU Water Framework Directive, a number of shallow lakes have been established within river systems in Denmark to reduce the amount of nitrogen being washed into the marine environment. However, several artificially established lakes have negative effects on anadromous fish species such as brown trout (Jepsen et al. 1998, Jepsen 2000, Olsson et al. 2001) and Atlantic salmon (Jepsen et al. 1998, Aarestrup et al. 1999, Koed et al. 2006). Thus, in 2 newly established lakes, loss of migrating brown trout smolts varied between 72 and $92 \%$ (Boel \& Koed 2013, Kristensen et al. 2014). The lakes were 1.4 and $3.04 \mathrm{~km}$ long, corresponding to mortality rates of $65 \% \mathrm{~km}^{-1}$ and $42 \% \mathrm{~km}^{-1}$, respectively. This mortality rate vastly exceeds the mortality rate experienced by salmonid smolts migrating in rivers $\left(0.3-7 \% \mathrm{~km}^{-1}\right.$; Thorstad et al. 2012). High mortality among anadromous fish in lakes is mainly caused by predation from fish, e.g. northern pike Esox lucius and pikeperch Sander lucioperca, as well as piscivorous birds, e.g. grey herons Ardea cinerea and great cormorants Phalacrocorax carbo. Some studies have even suggested that piscivorous salmonids actively optimize feeding and growth during recurring annual periods of high abundance of prey, for instance during the migration of smolts (Armstrong \& Bond 2013, Armstrong et al. 2013). Whether lakes within the rivers cause increased mortality of migrating juvenile North Sea houting has not been investigated, but needs to be addressed in order to improve restoration practices. Similarly, the effect of lakes on migrating adult North Sea houting has not been investigated, although lakes could potentially induce high mortality caused by predation from e.g. cormorants and northern pike.

Whether all North Sea houting in Danish rivers develop increased hyperosmotic tolerance and migrate into the Wadden Sea as juveniles, or a fraction stays within the rivers for an extended period of time, is unknown. However, Borcherding et al. (2008) analysed scales from North Sea houting sampled in the Dutch Lake IJsselmeer and established that North Sea houting in this area are, in fact, partial migrants. The authors distinguished between 3 different migration patterns: (1) individuals that migrated into seawater at an early age, (2) individuals that migrated into seawater at a much older age $(30-35 \mathrm{~cm}$ total length) and (3) individuals that never left freshwater. Borcherding et al. (2008) also analysed North Sea houting from the Danish Rivers Varde and Ribe, all of which migrated into seawater at an early age (35-40 mm). However, only 2 individuals from each of the 2 Danish rivers were analysed. The North Sea houting from Lake IJsselmeer originate from stocking of fry from the only indigenous population left in the Danish River Vidaa, which also supplied stocking material to the River Varde. It can therefore not be ruled out that the Danish populations also exhibit more variation in life history strategy and migration behaviour than just one strategy of migrating into the Wadden Sea at an early age. Identifying whether this is the case and describing the habitat use of the individuals staying in freshwater would provide valuable information for management and conservation.

In the Wadden Sea, pronounced regional differences in salinity prevail, and salinity fluctuates extensively within localities over time. For instance, salinity in Ho Bay, into which the River Varde empties, ranged between 8.5 and 30.8 ppt from May 1990 to December 2006. Mean salinity over the period was 21.3 ppt. In contrast, salinity in Lister Deep in the outer parts of the Wadden Sea ranged between 23.5 and $33.8 \mathrm{ppt}$ over the same period, with a mean salinity of 28.9 ppt. Similar salinities occur in central locations within the Wadden Sea: Højer Deep (mean 28.0 ppt), Ribe Deep (mean 27.8 ppt) and Ribe Strøm (mean 29.3 ppt) (data source: Danish Nature Agency). In 255-273 d old juveniles exposed to gradually increasing salinities, mortality was $25 \%$ when salinity reached 25 ppt. A further increase to $30 \mathrm{ppt}$ did not induce further mortality when taking into account the increased mortality in the control group at this point in time. The increased mortality at 25 ppt could indicate that a fraction of the juveniles had not yet fully acclimated to high salinities. Given the geographically variable salinities, juveniles migrating into the Wadden Sea might be restricted periodically to estuaries and the inner parts of the Wadden Sea until their hyperosmotic tolerance has improved. The behaviour and habitat requirements of juvenile North Sea houting in the marine environment are completely unknown, and further research is necessary to clarify whether specific management and conservation efforts concerning this particular life stage are needed.

The adult North Sea houting is typically considered an anadromous coregonid with an exceptional osmoregulatory capacity allowing it to migrate directly into $\geq 32$ ppt saltwater (Jensen et al. 2003, Hansen et al. 2008, Jepsen et al. 2012). However, experimental analyses of osmoregulatory mechanisms and their 
limits in adult North Sea houting do not exist. Whether salinity tolerance increases from juveniles to adults has not been investigated, and it remains unknown whether the geographical distribution of adults within the Wadden Sea is restricted by regional salinity gradients. Local fishermen in the area around Ho Bay report that several years ago, when populations were bigger, adult North Sea houting were regularly caught in fish traps targeting European eel Anguilla anguilla. However, bycatch of adult North Sea houting in the outer parts of the Wadden Sea was extremely rare. Further, no North Sea houting has been registered in thousands of fish surveys carried out for decades either within the outer parts of the Wadden Sea or in the North Sea just outside the Wadden Sea (H. Asmus \& H. Sparholt pers. comm.). On the other hand, passive integrated transponder tagging has identified individuals straying to other rivers, implying that these fish have entered the North Sea for at least a short period of time (Jepsen et al. 2012). Gaining knowledge on the osmoregulatory capacity of adult North Sea houting and their migration behaviour within the Wadden Sea would improve our understanding of the species and be invaluable in setting up appropriate management schemes and possibly establishing areas of increased protection.

In this study, we found that the timing of the arrival of the early life stages of North Sea houting into the Wadden Sea is highly critical and potentially associated with high mortalities if larvae and juveniles are carried into saltwater prematurely. The decline of the Danish populations of North Sea houting is most likely due to high mortality at early life stages, as adult survival seems to be high (Jepsen et al. 2012). While additional study is warranted, mortality due to premature or too abrupt transfer into saltwater might be responsible for at least part of the population decline and needs to be further investigated to produce science-based conservation strategies and plans for habitat restoration.

Acknowledgements. We thank Michael Deacon at the Danish Nature Agency for valuable comments on a previous version of the manuscript. J.C.S. was supported by a grant (SFRH/BPD/89473/2012) from the Foundation for Science and Technology (FCT) in Portugal.

\section{LITERATURE CITED}

Aarestrup K, Jepsen N, Rasmussen G, Økland F (1999) Movements of two strains of radio tagged Atlantic salmon, Salmo salar L., smolts through a reservoir. Fish Manag Ecol 6:97-107
Armstrong JB, Bond MH (2013) Phenotype flexibility in wild fish: Dolly Varden regulate assimilative capacity to capitalize on annual pulsed subsidies. J Anim Ecol 82:966-975

Armstrong JB, Schindler DE, Ruff CP, Brooks GT, Bentley KE, Torgersen CE (2013) Diel horizontal migration in streams: juvenile fish exploit spatial heterogeneity in thermal and trophic resources. Ecology 94:2066-2075

Boel M, Koed A (2013) Smolttabet i Årslev Engsø. En sammenligning af den nydannede engsø i 2004 og den etablerede engsø i 2011. DTU Aqua Rep 260-2013. National Institute of Aquatic Resources

Borcherding J, Scharbert A, Urbatzka R (2006) Timing of downstream migration and food uptake of juvenile North Sea houting stocked in the Lower Rhine and the Lippe (Germany). J Fish Biol 68:1271-1286

Borcherding J, Pickhardt C, Winter HV, Becker JS (2008) Migration history of North Sea houting (Coregonus oxyrinchus L.) caught in Lake IJsselmeer (The Netherlands) inferred from scale transects of $88 \mathrm{Sr}: 44 \mathrm{Ca}$ ratios. Aquat Sci 70:47-56

Borcherding J, Breukelaar AW, Winter HV, König U (2014) Spawning migration and larval drift of anadromous North Sea houting (Coregonus oxyrinchus) in the River IJssel, the Netherlands. Ecol Freshw Fish 23:161-170

> De Groot SJ (2002) A review of the past and present status of anadromous fish species in the Netherlands: Is restocking the Rhine feasible? Hydrobiologia 478:205-218

De Groot SJ, Nijssen H (1997) The North Sea houting, Coregonus oxyrinchus, back in the Netherlands (Pisces, Salmoniformes, Salmonidae). Bull Zool Mus Univ Amst 16:21-24

Dierking J, Phelps L, Præbel K, Ramm G and others (2014) Anthropogenic hybridization between endangered migratory and commercially harvested stationary whitefish taxa (Coregonus spp.). Evol Appl 7:1068-1083

Etheridge EC, Adams CE, Bean CW, Durie NC and others (2012) Are phenotypic traits useful for differentiating among a priori Coregonus taxa? J Fish Biol 80:387-407

Freyhof J, Schöter C (2005) The houting Coregonus oxyrinchus (L.) (Salmoniformes: Coregonidae), a globally extinct species from the North Sea basin. J Fish Biol 67: 713-729

Grøn P (1987) Saving the North Sea houting. In: Tougaard S, Asbirk S (eds) Proc 5th Int Wadden Sea Symp, 29 Sep-3 Oct 1986, Esbjerg, Denmark, p 147-159

Hansen HO (2006) The houting project - the second largest nature restoration project in Denmark. Meanders. Newsl SIL Working Group Conserv Manag Running Waters 13: 2-5

> Hansen MM, Nielsen EE, Mensberg KLD (2006) Underwater but not out of sight: genetic monitoring of effective population size in the endangered North Sea houting (Coregonus oxyrhynchus). Can J Fish Aquat Sci 63: 780-787

> Hansen MM, Fraser DJ, Als TD, Mensberg KLD (2008) Reproductive isolation, evolutionary distinctiveness and setting conservation priorities: the case of European lake whitefish and the endangered North Sea houting (Coregonus spp.). BMC Evol Biol 8:137

> Jacobsen MW, Hansen MM, Orlando L, Bekkevold D, Bernatchez L, Willerslev E, Gilbert MT (2012) Mitogenome sequencing reveals shallow evolutionary histories and recent divergence time between morphologically and ecologically distinct European whitefish (Coregonus spp.). Mol Ecol 21:2727-2742 
Jäger T (1999) Die Wiedereinbürgerung des Nordseeschnäpels. In: Verband Deutscher Sportfischer (ed) Fisch des Jahres 1999: der Nordseeschnäpel. Verband Deutscher Sportfischer, Offenbach, p 3-11

Jensen AR, Nielsen HT, Ejbye-Ernst M (2003) National management plan for the houting. Ministry of the Environment, Forest and Nature Agency, County of Southern Jutland and County of Ribe, Ribe

Jepsen N, Aarestrup K, Økland F, Rasmussen G (1998) Survival of radio-tagged Atlantic salmon (Salmo salar L.) and trout (Salmo trutta L.) smolts passing a reservoir during seaward migration. Hydrobiologia 371/372: 347-353

Jepsen N, Pedersen S, Thorstad E (2000) Behavioural interactions between prey (trout smolts) and predators (pike and pikeperch) in an impounded river. Regul Rivers Res Manag 16:189-198

> Jepsen N, Deacon D, Koed A (2012) Decline of the North Sea houting: protective measures for an endangered anadromous fish. Endang Species Res 16:77-84

Koed A, Baktoft H, Bak BD (2006) Causes of mortality of Atlantic salmon (Salmo salar) and brown trout (Salmo trutta) smolts in a restored river and its estuary. River Res Appl 22:69-78

Kristensen M, Koed A, Mikkelsen JS (2014) Egå Engsø - tab af havørredsmolt i en Vandmiljøplan II-sø. DTU Aqua Rep 276-2014. National Institute of Aquatic Resources

Marshall WS (1995) Transport processes in isolated teleost epithelia: opercular epithelium and urinary bladder. In: Wood CM, Shuttleworth TJ (eds) Fish physiology, Vol 14. Cellular and molecular approaches to fish ionic regulation. Academic Press, New York, NY, p 1-23

$>$ McCormick SD (1994) Ontogeny and evolution of salinity tolerance in anadromous salmonids: hormones and heterochrony. Estuaries 17:26-33

Nielsen C, Holdensgaard G, Petersen HC, Björnsson BT, Madsen SS (2001) Genetic differences in physiology, growth hormone levels and migratory behaviour of Atlantic salmon smolts. J Fish Biol 59:28-44

Nielsen C, Aarestrup K, Nørum U, Madsen SS (2003) Premigratory differentiation of wild brown trout into migrant and resident individuals. J Fish Biol 63:1184-1196

Nielsen C, Aarestrup K, Nørum U, Madsen SS (2004) Future migratory behaviour predicted from premigratory levels of gill $\mathrm{Na}+\mathrm{K}+$-ATPase activity in individual wild brown trout (Salmo trutta). J Exp Biol 207:527-533

Olsson IC, Greenberg LA, Eklöv AG (2001) Effect of an artificial pond on migrating brown trout smolts. N Am J Fish Manag 21:498-506

Østbye K, Bernatchez L, Næesje TF, Himberg JM, Hindar K (2005) Evolutionary history of the European whitefish Coregonus lavaretus (L.) species complex as inferred

Editorial responsibility: Steven Cooke,

Ottawa, Ontario, Canada from mtDNA phylogeny and gill-raker numbers. Mol Ecol 14:4371-4387

Østbye K, Amundsen PA, Bernatchez L, Klemetsen A and others (2006) Parallel evolution of ecomorphological traits in the European whitefish Coregonus lavaretus (L.) species complex during postglacial times. Mol Ecol 15: 3983-4001

Pihl S, Ejrnæs R, Søgaard B, Aude E, Nielsen KE, Dahl K, Laursen JS (2000) Naturtyper og arter omfattet af EFHabitatdirektivet. Indledende kortlægning og foreløbig vurdering af bevaringsstatus. Rep no. 322. National Environmental Research Institute of Denmark, Aarhus

> Poulsen SB, Svendsen JC, Jensen LF, Schulz C, JägerKleinicke T, Schwarten H (2010) Effects of food deprivation on refuge use and dispersal in juvenile North Sea houting Coregonus oxyrinchus under experimental conditions. J Fish Biol 77:1702-1708

Poulsen SB, Jensen LF, Schulz C, Deacon M and others (2012) Ontogenetic differentiation of swimming performance and behaviour in relation to habitat availability in the endangered North Sea houting (Coregonus oxyrinchus). Aquat Living Resour 25:241-249

Rasmussen PC (2004) Opvækstområder for snæbel i Vidå og Ribe Å. Report for the County of Southern Jutland, County of Ribe and the Danish Forest and Nature Agency

Schmidt-Nielsen K (1997) Animal physiology. Adaptation and environment. Cambridge University Press, New York, NY

Shapiro SS, Wilk MB (1965) An analysis of variance test for normality. Biometrika 52:591-599

Shrimpton JM, Björnsson BT, McCormick SD (2000) Can Atlantic salmon smolt twice? Endocrine and biochemical changes during smelting. Can J Fish Aquat Sci 57: 1969-1976

> Thorstad EB, Whoriskey F, Uglem I, Moore A, Rikardsen AH, Finstad B (2012) A critical life stage of the Atlantic salmon Salmo salar: behaviour and survival during the smolt and initial post-smolt migration. J Fish Biol 81: 500-542

> Usher ML, Talbot C, Eddy FB (1988) Drinking in Atlantic salmon smolts transferred to seawater and the relationship between drinking and feeding. Aquaculture 73: 237-246

Varsamos S, Nebel C, Charmantier G (2005) Ontogeny of osmoregulation in postembryonic fish: a review. Comp Biochem Physiol Part A Mol Integr Physiol 141:401-429

Yeoh CG, Kerstetter TH, Loudenslager EJ (1991) Twentyfour hour seawater challenge test for coastal cutthroat trout. Prog Fish-Cult 53:173-176

Zydlewski J, McCormick SD (1997) The ontogeny of salinity tolerance in the American shad, Alosa sapidissima. Can J Fish Aquat Sci 54:182-189

Submitted: March 12, 2015; Accepted: July 13, 2015 Proofs received from author(s): September 4, 2015 